\title{
La familia influencia el patrón de consulta médica de sus integrantes
} Objetivo
Examinar el grado de influencia de la familia en el uso individual del
sistema de atención primaria.

\section{Diseño}

Estudio de cohorte retrospectiva de todas las consultas realizadas en un año (2001) en 104 centros de atención primaria.

\author{
Lugar \\ Centros de atención primaria de Holanda.
}

\section{Participantes}

Se incluyeron 42.262 familias con al menos un niño entre los 2 y los 21 años.

\section{Evaluación de factores pronósticos}

Se utilizó un modelo de análisis en multiniveles para evaluar si existía una relación entre la frecuencia de contactos con el sistema de salud de los individuos dentro de las familias y dentro de las áreas programáticas de los centros de salud. La fuente de datos fue el Censo Nacional de Prácticas Generales de Holanda.

\section{Medición de resultados principales}

Influencia familiar en la frecuencia individual de contactos con el

\section{Comentario}

tactos con el sistema de salud entre padres e hijos.

\section{Resultados}

Luego de ajustar por edad y sexo, un $18 \%$ de la frecuencia de consultas puede atribuirse a la influencia de la familia (la frecuencia de consultas de los miembros de una familia se parecen entre sí y difieren de las de otras familias), un $6 \%$ se atribuye a diferencias entre los centros de salud y un $73 \%$ a factores individuales (ver tabla). Si bien todos los miembros de la familia presentaron una correlación en el número de consultas, la asociación más fuerte se presentó entre madres e hijos y entre hermanos.

Tabla 1. Resultados principales

\begin{tabular}{|l|c|c|c|} 
& Nivel familiar & $\begin{array}{c}\text { Nivel centro de } \\
\text { salud }\end{array}$ & Wivel individual \\
\hline Porcentaje de varianza* & $18 \%$ & $6 \%$ & $73 \%$ \\
\hline
\end{tabular}

*Ajustado por sexo y edad

\section{Conclusiones}

La influencia de la familia tiene un peso considerable en relación a la frecuencia de consulta de sus individuos.
Es un concepto ya conocido que la familia influencia de manera compleja los modos y patrones de consulta de sus integrantes, así como sus enfermedades y la forma de enfrentarlas. Varios estudios mostraron que los miembros de una misma familia presentan patrones de morbilidad similares a lo largo del tiempo, que van conformado "modos" de acercarse al sistema de salud, pasibles de ser transmitidos a la siguiente generación. ${ }^{1}$ Estos patrones replicativos se relacionan con el tipo de enfermedad; por ejemplo, las esposas de diabéticos tienen el doble de riesgo de padecer la enfermedad de sus esposos que las de no diabéticos. ${ }^{2}$ También se relacionan con la modalidad de acercamiento individual al sistema de salud (familias policonsultadoras).

Sin embargo, hasta este trabajo no se había tratado de cuantificar el impacto de la familia en el modo en que sus miembros se acercan al sistema de salud. Además, la sociedad ha cambiado hacia modelos diferentes de familia (familia ampliada, monoparentales, mayor individualización de sus integrantes) y esto podría afectar el grado de influencia familiar en la forma de acercamiento de sus miembros a los sistemas de salud.

Este estudio observacional trató de describir el funcionamiento de las familias en relación a su frecuencia de consulta al buscar patrones similares entre los diferentes miembros de una familia. También estudió la posible influencia del centro de salud donde era atendida. La respuesta a estas preguntas parece positiva, y conocer los modos de interacción de la familia permite encarar la práctica médica en forma más eficaz ya que puede reconocer, por ejemplo, el potencial familiar de perpetuar la enfermedad de sus individuos así como su capacidad de actuar como unidad de restablecimiento de salud individual ${ }^{3}$. Otro ejemplo en donde conocer los patrones de consulta familiares importante es el tema de los policonsultadores; se podría ampliar el análisis al nivel familiar en estos casos para detectar esas familias y actuar a ese nivel.

¿Por qué las familias tienen patrones de consulta similares? Sus miembros presentan características homogéneas heredadas o adquiridas (los cónyuges se eligen entre sí por características en común). Además la familia va adquiriendo actitudes, pensamientos, gustos, hábitos parecidos a lo largo de la convivencia y comparte circunstancias físicas, económicas y sociales en la vida diaria que pueden llevar al mejoramiento o empeoramiento de la salud de sus miembros ${ }^{4}$. Esto puede condicionar el tipo de centro de salud o médico de atención primaria al que acudan.

Estudios como éste, que utilizan un interesante modelo de análisis, podrían aumentar la evidencia sobre la efectividad de intervenir en el nivel familiar y reorientar la medicina basada en la evidencia incorporando la influencia familiar como otra variable de análisis. Teniendo en cuenta a la familia en esta clase de estudios podría permitir evaluar otras estrategias de prevención, tratamiento y recuperación de las enfermedades, además de facilitar la integración del conocimiento "biomédico" con el de la teoría de la intervención familiar, por ejemplo crear un recordatorio para el médico en la historia clínica si aparece algún patrón "similar" de consulta en los miembros de una familia.

\section{Conclusiones del comentador}

La familia influencia significativamente la frecuencia de consulta de sus individuos, sería deseable investigar si la intervención en el nivel familiar puede modificar el patrón individual de consultas así como la morbilidad.

Victoria Wurcel [ Fellow de Investigación. Unidad de Medicina Familiar y Preventiva del Hospital Italiano de Buenos Aires ]

Wurcel V. La familia influencia el patrón de consulta médica de sus integrantes. Evid. actual. práct. ambul. 2005;8:76. Comentado de Cardol M, Groenewegen P, de Bakker D et al. Shared help seeking behaviour within families: a retrospective cohort study. BMJ 2005;330:882. PMID: 15772114

\section{Referencias}

1. Hippisley-Cox J, Coupland C, Pringle M, Crown N, Hammersley V. Married couples' risk of same disease: cross sectional study. BMJ 2002;325:636-40.

2. Asya Khan, B. Are Spouses of Patients With Type 2 Diabetes at Increased Risk of Developing diabetes? Diabetes Care 2003:26; 3:92-4

3. Asen k. Intervención familiar. Paidós. Primera Ed.1997.

4. Ortega Bevia F.Terapia familiar sistémica. Universidad de Sevilla. Segunda Ed. 2001. 